\title{
Theory-driven Determinants of School Students' STEM Career Goals: A Preliminary Investigation
}

\author{
Vesife Hatisaru ${ }^{1 *}$ \\ ${ }^{1}$ University of Tasmania, AUSTRALIA \\ *Corresponding Author: vesife.hatisaru@utas.edu.au \\ Citation: Hatisaru, V. (2021). Theory-driven Determinants of School Students' STEM Career Goals: A \\ Preliminary Investigation. European Journal of STEM Education, 6(1), 02. \\ https://doi.org/10.20897/ejsteme/9558
}

Published: January 15, 2021

\begin{abstract}
This study investigated Turkish school students' attitudes towards STEM disciplines and careers and explored determinants of students' STEM career goals. In total, 117 lower secondary school students (aged 11 to 14) completed the STEM Semantic Survey including an open-ended question about their career intention after high school and the reasons for their goals. Using the conceptualisation of the influences of behavioural, personal, and contextual variables in career choice decisions, the students' descriptions of career goal reasons were presented to elaborate on the variables that influence their STEM career goals. Attitudes towards individual STEM disciplines were from moderate to high and towards STEM careers were high. The gender difference was negligible. One of the key determinants of students' career intentions was interests, involving interest in a particular career (e.g., architect) and career-relevant activities (e.g., planning, drawing, and designing) or subjects (e.g., mathematics). Larger, societal influences (altruism and patriotism) were among the motives of students' career goals. Implications for research, practice, and policymaking were presented.
\end{abstract}

Keywords: draw a mathematics classroom, social cognitive career theory, STEM career goals, school students

\section{INTRODUCTION}

STEM (science, technology, engineering, and mathematics) capability is one of the key competences necessary for functioning effectively in the modern world and contributing to technological and economical high productivity (Jolly, Campbell, \& Perlman, 2004; Office of the Chief Scientist, 2012). STEM capability can also be a mean of self-fulfilment and personal enrichment. Enhancing school students' STEM competences, thus, meets not only societal, but also individual needs (Sjaastad, 2012). Many countries consider the issue of competence in STEM as important and incorporate strategies for its development during schooling, at the highest policy level. Despite these influences, there remains a lack of interest in students towards STEM subjects. Both policy documents and research studies indicate international declines in degrees awarded from STEM programs (Prieto \& Dugar, 2017). Reports conclude that admission in and graduation from STEM-related areas have fallen in Australia (Australian Academy of Science, 2016; Barrington \& Evans, 2014), the USA (Christensen, Knezek, \& Tyler-Wood, 2014), Europe (Kearney, 2016), and in Turkey (Kivanc, Sener, Mumcuogullari, \& Sunacoglu, 2017). Exploring what motivates school students to learn STEM subjects, continues to be a concern for researchers, educators, and policymakers. There is a need to better understand why students would choose to study STEM-related areas, and what opportunities and resources in schools encourage them to enrol and remain in STEM fields. 


\section{PURPOSE AND RESEARCH QUESTIONS}

The aims of this paper are: (1) to investigate school students' attitudes towards STEM disciplines and careers; (2) to describe behavioural (self-efficacy, outcome expectations, interests, and goals), personal (gender), and environmental (larger, societal context) influences on students' career intents; and (3) to assess the suitability of a theoretical framework for studying the factors that influence school students' STEM career goals. The overall objective is to increase understanding of theory-driven determinants of school students' career intentions concerning STEM. The STEM Semantic Survey (Christensen et al., 2014) provided data from a sample of Turkish lower secondary school students (aged 11 to 14), in the Draw a Mathematics Classroom study which is reported elsewhere (Hatisaru, 2020a; in press). Students' responses to the Survey items are analysed in light of the above aims. As a theoretical base, the conceptualisation of their career choice is based on the behavioural, personal, and environmental determinants, as suggested by Lent, Brown, and Hackett $(1994,2000)$. This framework is utilised to discuss what factors influence students' intentions in relation to pursuing a STEM career. The research questions that guide the study are:

1. What are students' attitudes towards individual STEM disciplines and STEM careers? How do their attitudes vary by gender?

2. What are students' intended career choice (STEM or non-STEM)? How do their choice vary by gender?

3. What are the determinants of their career goals?

\section{BACKGROUND}

Dispositions towards STEM have been explored in different ways during the last decades. Much has been written about what factors contributing to students' orientations to STEM subjects and careers. There has been consistent evidence that students' perceptions of psychosocial aspects of the classroom environment (e.g., teacher support, student cohesiveness, and competitiveness) are associated with students' STEM learning outcomes (Fraser, 2014) such as attitudes, interest, or motivation for learning (e.g., Afari, Aldridge, Fraser, \& Khine, 2013). The perceived teaching and learning practices in STEM classrooms have been received attention as well. Lyons (2006) examined experiences of school science reported by high school students in Sweden, Australia, and England in three interpretive studies. Three characteristics of school science emerged from students' narrative reflections: the transmissive pedagogy; decontextualized content; and unnecessary difficulty of school science. These perceived classroom experiences were found to have negative influences on students' interest and enrolments in both in high school and tertiary level science courses.

Various other disparate explanations have been offered. Informal learning experiences and afterschool programmes in STEM (e.g., robotics summer camps and media design projects) were found positively influence high school students' attitudes towards science and technology and interest in an engineering career (Ayar, 2015; Karahan, Bilici, \& Unal, 2015; Prieto \& Dugar, 2017). Primary and lower secondary students evaluated science fairs positively and expressed a wish that science affairs became more regular (Gülgün et al., 2020). For high school graduates, choosing a STEM major was influenced by intentions to major in STEM and high school mathematics achievement. Intent to major in STEM was impacted by grade 12 mathematics achievement, having mathematics and science courses, and mathematics self-efficacy. All these three variables were influenced by early achievement in and attitudes towards mathematics (Wang, 2013). Thus, all self-efficacy, outcomes expectations, and significant persons have been of importance. Among a group of American and Turkish high-ability high school students, selfmotivation (inclination) was the most influential factor in American students' interest to STEM careers, while it was mother's education level for Turkish students. The American students' interests to STEM careers were owing to their self-motivation to undertake STEM careers and school-related factors (e.g., STEM clubs, fairs). The Turkish students' interests were predominantly influenced by potential professional income and social expectations (influence of others involving parents, teachers, peers, and relatives) (Bahar \& Adiguzel, 2016). Teachers and parents were the main source of inspiration for Norwegian university students' STEM-related educational choice. Parents who engaged in STEM themselves were models for their children making the STEM-related choices familiar to them. Teachers were also model for students who displayed how STEM might bring fulfilment in individuals' lives and who gave students positive STEM learning experiences (Sjaastad, 2012). Parents or family members were similarly influential on middle school students' future career plans from a diverse and disadvantaged rural community (Kier \& Blanchard, 2021).

STEM dispositions have often been investigated with respect to gender (Tripney et al., 2010). There have been some inconsistencies in gender-related findings. While some studies have revealed that females were less positive than males in pursuing careers in STEM (Sadler, Sonnert, Hazari, \& Tai, 2012), other studies showed that females' semantic perceptions of pursuing STEM careers were significantly more positive than males (Christensen et al., 2014). K-12 educators and pre-college STEM outreach programs played a role in influencing and motivating 
undergraduate female students - as well as male students - to enrol and persist in college level STEM degree programmes (Edzie, 2014). There have been calls that school students need to be motivated towards STEM subjects as those students were more likely to pursue STEM-related careers (Eurydice, 2011; Maltese \& Tai, 2010; Prieto \& Dugar, 2017). Teachers of STEM have been encouraged to move away from teacher-directed pedagogies and "make learning active" (Maltese \& Tai, 2010, p. 900) to improve student motivation to and interest in STEM subjects (Hasni \& Potvin, 2015). Effective pedagogies have included: engaging students in the learning processes and promoting authentic scientific inquiry (Sirinterlikci, Zane, \& Sirinterlikci, 2009); embedding learning in concrete and meaningful problems or tasks and ensuring students collaborate with others to solve problems (Hatisaru \& Kucukturan, 2011; Hmelo-Silver, 2004); enabling students to link the knowledge they learn at school with their lives outside the school (Potvin \& Hasni, 2014); and teaching STEM in an integrated way (Knipprath et al., 2018). Students in different educational and national contexts, nevertheless, have responded to what their context provides to them in different ways (Lent et al., 2000; Thomas \& Watters, 2015).

In Turkey, lower secondary education lasts for four years (grades 5 to 8 , aged 10 to 15) and is provided by secondary schools. Mathematics and science are taught as a mandatory and major subject at all levels of schooling and is tested by national examinations at the end of lower and upper secondary education. Mathematical and science questions make up a good deal of the questions for both high school and university entrance exams (European Schoolnet, 2018). Teaching practices have been largely influenced by these nation-wide standardised exams. It is common for teachers to rely on lecture-style teaching and emphasising the procedural knowledge and correct use of procedures for preparing students for examinations. (Ayar, 2015; Kearney, 2016). Despite the broad agreement that teacher-directed teaching practices negatively impact students' attitudes (e.g., Hasni \& Potvin, 2015), Turkish school students' attitudes towards science and mathematics yet are generally positive (Hatisaru, 2020b; Mullis, Martin, Foy \& Hooper, 2016; Sjøberg \& Schreiner, 2010). Students are interested in studying STEM subjects at university (Kearney, 2016). STEM-related careers, especially engineering, are appealing to many students (Ayar, 2015). Nevertheless, the number of graduates and new admissions in technical and quantitative fields have been disproportionately low. In 2012, for example, 80037 high school graduates entered various types of engineering degree programs (e.g., mechanical, chemical, civil, petroleum, and computer) of which less than a half graduated (36 786) (Ayar, 2015). Across the country, between 2013 and 2016, the percentage of STEM graduates was only about $17 \%$. The employment market projections for STEM occupations has been expected to be about one million between 2016 and 2023, resulting in a shortfall of around 31\% of this requirement (300 000) (Kivanc et al., 2017).

While previous research has suggested that positive orientations towards STEM are fundamental to students' entrance and persistence in, and completion of STEM-related fields (success), this study suggests that success is based on various interrelated factors. The current paper offers additional empirical evidence exploring school students' STEM career intents by applying a theory which considers various aspect of career choice behaviours. The paper contributes to understanding why students' positive orientations to science, mathematics, and related quantitative disciplines have not necessarily been translating into success. Theoretical underpinning follows this section.

\section{THEORETICAL PERSPECTIVE}

One contemporary theoretical approach to individuals' career interest is Lent et al.'s (1994) Social Cognitive Career Theory (SCCT). SCCT represents a long-lasting effort to understand the mechanisms through which individuals develop interests, make choices, succeed in educational and career pursuits (Lent et al., 1994). SCCT has its root predominantly in Bandura's (1986) general social cognitive theory, which suggests the ways in which individuals, their behaviour, and environments affect one another. SCCT is a testable theory that attempts to explain the behavioural (social cognitive) and other personal and environmental variables behind career interest, choice, and performance. Several studies have utilised SSCT to explore how individuals develop occupational pursuits, make and/or remake vocational choices, and achieve career success (Lent, 2005). It has been used in STEM education for measuring, for example, high school (e.g., Bahar \& Adiguzel, 2016) and college level (e.g., Lent, Sheu, Gloster, \& Wilkins, 2010; Wang, 2013) students' (involving adults, Sasson, 2020) dispositions and career aspirations related to STEM. In this paper, SCCT conceptualisation was applied to describe the determinants of lower secondary students' STEM career intentions.

SCCT has two complementary aspects of theoretical analysis. The first aspect presents behavioural variables that give individuals personal control in their career choice and development: self-efficacy, outcome expectations, interests, and goals. The second aspect involves several other variables that affect individuals' career-related interests and choice behaviours such as personal history (e.g., gender, race, and pre-dispositions) and environmental or contextual features (e.g., culture, educational climate, and particular learning experiences). SCCT 
posits that behavioural, environmental, and personal variables influence one another through complex, reciprocal relations (Lent et al., 1994).

Self-efficacy appraisals are related to individuals' response capabilities, i.e. "Can I do this?” (Lent et al., 1994, p. 83), that serving as an influential determinant of occupational behaviours. Among others, self-efficacy beliefs are the most focal or pervading in the mechanism of human agency. Individuals do act or show perseverance in the face of career-related difficulties, only if they believe they can produce desired outcomes by their actions. Thus, efficacy beliefs play a central role in career choice and development not only in their own right, but also their impact on other variables (Bandura et al., 2001). Outcome expectations are potent motivators and involve the assumed results of performing certain prospective actions, i.e. "If I do this, what will happen?" (Lent et al., 1994, p. 83). Lent et al. (1994) cited Bandura's (1986) three types of outcomes expectations: physical (e.g., monetary); social (e.g., approval of significant others); and self-evaluative (self-satisfaction). Lent et al. (2000) expanded the theory in later years to include ultimate, distal outcome expectations that incline individuals toward a certain goal. For example, one may want to become a doctor by being attracted to its prestige and opportunity to help people that being a doctor is perceived as offering. According to Lent et al. (2000), these types of ultimate expectations correspond Bandura's self-evaluative or self-fulfilment expectations and help to sustain individuals along challenging career paths towards their long-term career intents. Anticipated working conditions and reinforces related to a particular career (e.g., favourable conditions) are additional distal outcome expectations that can be bases for career interests or choices. These types of expectations sometimes can be long-term wishes such as intending to major in a mathematics or science-related area believing that having in a degree in these fields allows someone to earn relatively more (Lent et al., 2000).

Goals are expressed choices, aspirations, career plans, and decisions, i.e. "I intend to major in an engineering field" (Lent et al., 2010, p. 390). By setting goals, individuals organise and guide their actions (e.g., attending trainings related to their goal) to sustain their goals in the long run, sometimes even with little external support, and to increase the chance of achieving the desired outcomes (Lent et al., 1994). Interests are patterns of likes and dislikes with respect to career-relevant activities and jobs. They can be influenced by individuals' career-relevant abilities, and thus individuals' career goals are likely to be prompted by their interests. For instance, one's social interests may lead to them to pursue a social-type vocation (Lent et al., 2000). According to SCCT, self-efficacy and outcome expectations give rise to interests and that each of these variables, along with environmental factors, help to shape educationally and vocationally relevant choices (Lent et al., 2010).

Environmental factors are both objective and subjective contextual influences. Objective aspects of the environment include the quality of educational experiences, parental behaviours, peer influences, and economic conditions (e.g., the financial support available to individuals for having career-related training) and can affect peoples' career choice or development (Lent et al., 2000). In their conceptualisation of the way of analysing student success in the sciences and quantitative subjects - the Engagement, Capacity, and Continuity Trilogy (the ECC Trilogy) - Jolly et al., (2004) underline the importance of objective contextual factors in career or academic success. The authors suggest that continuation in career-related subjects towards careers in those fields (success) could only be achieved within systems where individuals' goals complement with their career-related capacity and necessary resources are offered by the system.

The subjective environment refers to individual perceptions regarding opportunities, resources, or barriers that are provided in a certain environment. For example, some individuals succeed in environments where very limited resources available, while some fail in rich conditions. This relates to how they make sense of and respond to their environments (Lent et al., 2000). SCCT categorises environmental variables according to their relative proximity to the educational or career choice processes as: distal, background contextual influences; and proximal factors or affordances. Distal, background contextual factors involve role model presence and opportunities for engaging in particular academic or extracurricular activities. These factors can affect individuals' learning experiences through which their career-relevant self-efficacy and outcome expectations develop. Proximal contextual affordances (e.g., career network contacts) are important especially throughout active phases of career decision-making (Lent et al., 2000). Parenthetically, this study of lower secondary school students' career goals concentrates on distal, contextual factors. SCCT hypothesises that environmental variables can directly influence or moderate individuals' careerrelevant choices and associated actions. For example, an individual who perceives supportive environmental factors (e.g., adequate support systems) is more likely to translate their career aspiration into a goal, and their goal into related actions. Or an individual within a collectivist culture may prioritise the needs or preferences of others rather than their own personal career wishes (Lent et al., 2000).

Although STEM dispositions have stimulated much research in Turkey, as in other parts of the world, the critical theoretical ingredients of school students' STEM career choice intentions have not necessarily been incorporated into investigations. These efforts may fail to identify and mediate "the central variables that nurture and sustain occupational interests and choices" (Lent et al., 2010, p. 387). The present study builds upon earlier 
research by including a more complete picture of Turkish school students' interests and attitudes related to STEM disciplines and careers, applying SCCT (Lent et al., 1994).

\section{METHOD}

\section{Draw a Mathematics Classroom Study}

The Draw a Mathematics Classroom study (Hatisaru, in press) was designed to identify lower secondary school students' (grades 6 to 8 , aged 11 to 14) perceptions of instructional practices in the mathematics classroom by using a drawing technique. The research questions sought to determine, through the students' eyes, what teaching and learning practices, and teaching resources, including mathematical tasks and their representational forms (e.g., visual, symbolic), were used in mathematics classrooms. The Draw a Mathematics Classroom Test adapted from relevant research studies was used to collect the data. The test combined drawings with written responses. Participant students were asked to draw a picture of their mathematics classroom in where students learning and the teacher teaching. Next, they described their drawing: what the teacher was doing; what the students were doing; and what materials and tools they were using. On the back page of the Test, the STEM Semantic Survey (Christensen et al., 2014) was utilised (with permission). Only the responses to STEM Semantic Survey were analysed in this paper.

Three lower secondary schools (two public, one private) located in Ankara, the capital city, voluntarily participated in the study. The schools were co-educational metropolitan schools with a relatively middle socioeconomic population based on family income. The instrument was implemented in Turkish at the beginning of the 2018-2019 school year under the auspices of school principals. The counselling teachers at each school conducted the survey at a time convenient for the schools. It took approximately thirty minutes to complete the task.

In data analysis, a priori thematic saturation was employed to gauge the degree to which pre-determined codes or categories were sufficiently represented in the data (Saunders et al., 2017). Among the 400 drawings, similar student depictions and descriptions were seen repeatedly, so after the 120th occurrence, the relevant categories was considered to be saturated and the coding of the remaining drawings was terminated. Of the 120 student responses, three were excluded from the analysis because they contained minimal information (Hatisaru 2020a; in press). The sample was further reduced to a final size of 95 students in this paper, because 22 students were missing data in ten or more of the Survey items used in the analysis. The 95 students were comprised of male $(n=47)$ and female $(n=48)$ students across grade $6(n=12)$, grade $7(n=36)$, and grade $8(n=47)$. Participants were coded as S1, S2, S3, and so on.

\section{STEM Semantic Survey}

The STEM Semantic Survey includes five consistent adjective pairs for a target statement reflecting individuals' attitudes towards each individual STEM discipline: science; technology; engineering; and mathematics (e.g., see Table 1). The fifth scale in the Survey is STEM career scale with the target statement: "To me, a career in science, technology, engineering, or mathematics is:" The same adjective pairs are used for all five scales. On top of the Survey, an instruction is given: "Choose one circle between each adjective pair to indicate bow you feel about the object". All items in the Survey were rated on a 7-Strongly Agree to 1-Strongly Disagree scales. Christensen et al. (2014) reported internal consistency reliabilities for the five scales as follows: Alpha $=.90$ for Science; Alpha $=.89$ for Mathematics; Alpha=.93 for Engineering; Alpha=.89 for Technology; and Alpha=.92 for STEM career. According to the authors, these reliability estimates fell into the range of "very good" to "excellent" based on the Devellis' (1991) guideline (p. 175).

The STEM Semantic Survey was translated into Turkish by the author who is fluent in Turkish and English languages. An additional open-ended item was added to the Survey to gather the influence of SCCT variables on students' interest to STEM careers: "What career would you want to pursue after high school? Why?"

Table 1. Science scale in the STEM Semantic Survey

To me, SCIENCE is:

\begin{tabular}{llllllllll}
\hline 1. & fascinating & 1 & 2 & 3 & 4 & 5 & 6 & 7 \\
\hline 2. & appealing & 1 & 2 & 3 & 4 & 5 & 6 & 7 \\
\hline 3. & exciting & 1 & 2 & 3 & 4 & 5 & 6 & 7 & unappealing \\
\hline$* 4$. & means nothing & 1 & 2 & 3 & 4 & 5 & 6 & 7 & meanciting \\
\hline$* 5$. & boring & 1 & 2 & 3 & 4 & 5 & 6 & 7 \\
\hline
\end{tabular}




\section{Data Analysis}

\section{Analysis of Likert items}

To analyse students' attitudes towards STEM disciplines and careers, mean and standard deviations were computed. Two items in each scale were reverse scored (see Table 1, Items 4 and 5). After assessing normality of the distribution, by using the skewness and kurtosis method, the Independent Samples $t$ Test was run to test the statistical difference between the means of female and male students' attitudes. Adapting from Narli (2010), student mean attitude scores were then divided into three groups: high; moderate; and low, based on the number of scales in the STEM Semantic Survey (i.e. five). As each scale was 7-point Likert type, group span value was calculated as $7 / 3 \cong 2.33$. Group interval values were calculated accordingly as presented in Table 2 .

Table 2. Group boundary values

\begin{tabular}{lccc}
\hline Interval boundary value (IBV) & $1-2.99$ & $1-4.99$ & $5-7$ \\
\hline Group & High & Moderate & Low \\
\hline
\end{tabular}

Students' responses to the open-ended item in the Survey were analysed by using both qualitative and quantitative data analysis methods. The intended career choices were grouped into two: STEM and non-STEM professions (see below). One Sample Chi-Square Test was utilised to test the statistical difference between the observed frequencies in STEM and non-STEM career intentions. To test the statistical association between the observed frequencies in STEM and non-STEM career intents (2 categories) and gender ( 2 categories), Fisher's Exact Test was used.

\section{Analysis of open-ended item}

Deductive content analysis (Elo \& Kyngäs, 2007) was utilised for qualitative data analysis. Student responses to the open-ended item, about what career they would want to pursue after high school and why, were transcribed documented using excel spreadsheets and next translated into English. As noted earlier, expressed career choices (goals) (e.g., 'I want to study medicine') were grouped into two: STEM and non-STEM. Adapting from Grinis (2019), STEM careers were classified in this paper depending on the intensiveness of STEM courses in relevant undergraduate program. STEM careers were defined as the majors included in the instructional programs corresponding to sciences and quantitative disciplines involving biology, physics, computer sciences, mathematics, technology, and statistics. All other careers were classified as non-STEM.

In many student responses $(n=74)$ only one career name was expressed, while in 21 responses, two $(n=18)$ or three $(n=3)$ career names were mentioned. The stated careers in these 21 responses were mostly separable. Thus, they were grouped either as STEM (e.g., "Orthodontist or bio medical engineering because I have interest in [them] "S69, grade 7, boy) or non-STEM careers (e.g., "Design or Turkish language. I like fun subjects, find them easy" S41, grade 7, boy). In two student responses, however, intended careers could be grouped both into STEM and non-STEM categories (e.g., "Policeman [non-STEM] or surgeon [STEM] [career] interests me" S94, grade 7, girl). Responses such as: "I bave not decided yet" (S46, grade 8, girl); and "T do not know" (S73, grade 7, boy) $(n=5)$ were also available. These responses, together two dichotomous ones, were grouped as 'Other' $(n=7)$ and not included in the analysis. Based on the expressed STEM $(f=71)$ and non-STEM $(f=43)$ careers in the student responses, Wordles (Figure 1 and Figure 2) were created in which font size indicates word frequency.

The student responses were categorised into SCCT's behavioural variables: self-efficacy; outcome expectations; interests; and goals. A summary table of these variables, together associated sub-variables and representative examples, was presented in Appendix A. As already noted, goals were expressed career choices and had two categories: STEM and non-STEM professions. Goal interests were liking/disliking or interest/lack of interest in careers, career-relevant activities, and/or career-relevant subjects. Self-efficacy referred to the perceived personal capacity regarding an expressed career intent and constituted career fit, career-relevant self-efficacy or capability, and aptitude for the expressed career. Outcome expectations involved anticipations that certain financial or distal rewards would follow pursuing particular careers. Three types of distal expectations were evident in student responses: expected long-term benefits; favourable conditions; and ultimate wishes. Within the latter group, altruistic and patriotic motives (both are central to Turkish culture) (Evason, 2017) were among the determinants of students' expressed career intents (e.g., providing a contribution to people and/or country).

In a total of 20 response, only the career goal was given such as: "Doctor" (S112, grade 8, girl) or "President" (S60, grade 8 , boy), but no reason was provided. The 68 responses which provided a reason(s) for the intended career choice were analysed to ascertain determinants of students' career intentions. Where more than one reason was given, these responses were coded into more than one category to maximising the richness of the data. For example, "I want to become a lanyer because I like defending others and can defend well" (S5, grade 8, boy) was coded into 
European Journal of STEM Education, 2021, 6(1), 02

Table 3. Means and standard deviations of attitudes towards STEM disciplines and career

\begin{tabular}{|c|c|c|c|c|c|}
\hline & $\mathbf{N}$ & Minimum & Maximum & Mean & Std. dev \\
\hline Science & 95 & 5.00 & 35.00 & 12.75 & 6.96 \\
\hline Mathematics & 95 & 5.00 & 35.00 & 14.83 & 8.86 \\
\hline Engineering & 95 & 5.00 & 35.00 & 16.51 & 8.98 \\
\hline Technology & 95 & 5.00 & 35.00 & 14.58 & 8.84 \\
\hline Career & 95 & 5.00 & 35.00 & 13.37 & 6.84 \\
\hline Valid N (listwise) & 95 & & & & \\
\hline
\end{tabular}

Table 4. Attitudes towards STEM disciplines and career correspond to IBV and group

\begin{tabular}{lcc}
\hline & IBV & Group \\
\hline Science & 2.55 & High \\
Mathematics & 2.97 & High \\
Engineering & 3.30 & Moderate \\
Technology & 2.92 & High \\
Career & 2.67 & High \\
\hline
\end{tabular}

Table 5. Independent Samples t Test comparing female and male students' attitudes towards STEM disciplines and career

\begin{tabular}{|c|c|c|c|c|c|c|c|}
\hline & & $\mathbf{n}$ & $\overline{\boldsymbol{X}}$ & $\mathbf{S}$ & Sd & Sig & $\mathbf{P}$ \\
\hline \multirow{2}{*}{ Science } & Female & 48 & 13.13 & 7.79 & \multirow{2}{*}{91} & \multirow{2}{*}{.33} & \multirow{2}{*}{.744} \\
\hline & Male & 47 & 12.66 & 6.09 & & & \\
\hline \multirow{2}{*}{ Mathematics } & Female & 48 & 15.18 & 8.77 & \multirow{2}{*}{91} & \multirow{2}{*}{.34} & \multirow{2}{*}{.732} \\
\hline & Male & 47 & 14.54 & 9.16 & & & \\
\hline \multirow{2}{*}{ Engineering } & Female & 48 & 19.71 & 8.35 & \multirow{2}{*}{91} & \multirow{2}{*}{3.47} & \multirow{2}{*}{.001} \\
\hline & Male & 47 & 13.60 & 8.63 & & & \\
\hline \multirow{2}{*}{ Technology } & Female & 48 & 16.89 & 8.39 & \multirow{2}{*}{91} & \multirow{2}{*}{2.43} & \multirow{2}{*}{.017} \\
\hline & Male & 47 & 12.53 & 8.89 & & & \\
\hline \multirow{2}{*}{ Career } & Female & 48 & 14.19 & 6.77 & \multirow{2}{*}{91} & \multirow{2}{*}{1.01} & \multirow{2}{*}{.317} \\
\hline & Male & 47 & 12.75 & 6.97 & & & \\
\hline
\end{tabular}

two sub-variables: 'career-relevant activity interest' and 'career-relevant self-efficacy'. Frequencies were calculated and presented in Table 9 below.

\section{RESULTS}

An overview containing quantitative results regarding students' attitudes towards STEM disciplines and careers is given first. This is followed by an in-depth description of determinants of students' career choice intentions organised by the SSCT framework. The discussion of results follows this section.

\section{Attitudes towards STEM Disciplines and Careers}

The STEM Semantic Survey scale was rated from 1-Strongly agree to 7-Strongly disagree in this study. Lower mean values, thus, refer to more positive attitudes. The mean and standard deviation values for students are shown in 'Table 3. As shown in the table, students' attitudes towards mathematics (Mean=14.83) and technology (Mean=14.58) were very close. Among the four STEM disciplines, attitudes towards science were the most (Mean=12.75) while towards engineering were the least (Mean=16.51) positive. When grouped, students' attitudes towards science, mathematics, and technology were high, while towards engineering were moderate (Table 4).

Table 5 presents the differences between the means of female and male students' attitudes towards STEM disciplines and careers. As seen in the table, while the differences between the means for female and male students' attitudes towards science and mathematics were statistically insignificant, the differences towards engineering and technology were statistically significant. Female students scored higher on engineering $(\bar{X}=19.71)$ and technology $(\bar{X}=16.89)$ scales than male students $(\bar{X}=13.60$ and $\bar{X}=8.89$ respectively). These indicated that female students' attitudes towards engineering and technology were less positive than their male counterparts.

When grouped, both female and male students' attitudes towards science were found to be high. While male students' attitudes towards mathematics, engineering, and technology were similarly high, female students' attitudes towards those subjects were moderate (Table 6). 
Table 6. Attitudes towards STEM disciplines and career correspond to IBV and group by gender

\begin{tabular}{lllc}
\hline & & IBV & Group \\
\hline \multirow{2}{*}{ Science } & Female & 2.63 & High \\
& Male & 2.53 & High \\
\hline \multirow{2}{*}{ Mathematics } & Female & 3.04 & Moderate \\
& Male & 2.91 & High \\
\hline \multirow{2}{*}{ Engineering } & Female & 3.94 & Moderate \\
& Male & 2.72 & High \\
\multirow{2}{*}{ Technology } & Female & 3.38 & Moderate \\
& Male & 2.55 & High \\
\hline \multirow{2}{*}{ Career } & Female & 2.84 & High \\
& Male & 2.55 & High \\
\hline
\end{tabular}

Table 7. Intended career choice in whole sample

\begin{tabular}{lccc}
\hline & Observed N & Expected N & Residual \\
\hline STEM & 54 & 44,0 & 10,0 \\
Non-STEM & 34 & 44,0 & $-10,0$ \\
Total & 88 & & \\
\hline$\chi^{2}=4.55$, sd $=1, \mathrm{p}=.033$ & &
\end{tabular}

$\chi^{2}=4.55, \mathrm{sd}=1, \mathrm{p}=.033$

Table 8. Intended career choice by gender

\begin{tabular}{lcccc}
\hline & & STEM & non-STEM & Toplam \\
\hline \multirow{2}{*}{ Female } & $\mathrm{n}$ & 29 & 15 & 44 \\
& $\%$ & $65.9 \%$ & $34.1 \%$ & $100.0 \%$ \\
\hline \multirow{2}{*}{ Male } & $\mathrm{n}$ & 25 & 19 & 44 \\
& $\%$ & $56.8 \%$ & $43.2 \%$ & $100.0 \%$ \\
\hline \multirow{2}{*}{ Total } & $\mathrm{n}$ & 54 & 34 & 88 \\
& $\%$ & $61.4 \%$ & $38.6 \%$ & $100.0 \%$ \\
\hline
\end{tabular}

$\chi^{2}=.77, \mathrm{sd}=1, \mathrm{p}=.512$

Students' attitudes towards a STEM career were found to be the second most positive (Mean=13.37) (Table 3). The differences between the means for female and male students' attitudes towards a STEM career were statistically insignificant (Table 5). Both females and males had high attitudes towards a STEM career (Table 6). Additional statistical analyses confirmed students' positive attitudes towards a STEM career (see the next section).

\section{Intended Career Choice}

In their responses to the open-ended item, among 88 students, 54 of them referred to a STEM (e.g., engineer) and 34 of them to a non-STEM career goal (e.g., psychologist). One sample chi-square test result showed, among students, the difference between intending to pursue a STEM or non-STEM career was statistically significant $\left(\chi^{2}=4.55, \mathrm{p}<.033\right)$ (Table 7). This showed that participant students would more intend on pursuing STEM careers than non-STEM careers.

The statistical association showing how students' STEM and non-STEM career intentions vary by gender is presented in Table 8. As seen in the table, while 34.1\% of female students would want to choose a non-STEM career, $65.9 \%$ of them would prefer to pursue a STEM career. Male students similarly had more interest to STEM careers than non-STEM careers. While $43.2 \%$ of male students referred to a non-STEM career choice goal, $56.8 \%$ of male students mentioned a STEM career intent. The observed differences, however, were similar. The differences between female and male students' interest to pursue a STEM or non-STEM career were statistically insignificant $\left(\chi^{2}=.77, \mathrm{p}<.05\right)$.

\section{Determinants of Career Goals}

The various descriptions of either STEM or non-STEM career goal reasons in the open-ended question pointed to interests $(f=45,55.56 \%)$ (Table 9). Students expressed that the career choice was made primarily based on interest to a particular career $(f=19)$ and career-relevant activities $(f=19)$ or subjects $(f=7)$. Students often cited factors involving liking/interested in a certain career (e.g., "Medicine because it interest me" S106, grade 8, girl) and being interested in activities (e.g., "Paediatrician because I have interest in both children and medicine" S91, grade 7, girl) or liking/being good at specific subjects relevant to a career (e.g., "Engineering, because I am interested in mathematics" S15, grade 8 , girl) as reasons for intending to pursue a career after graduating from high school.

Several descriptions corresponded to expected future outcomes $(f=25,30.86 \%)$. Ultimate wishes $(f=21)$ were the most cited reasons as bases for choosing a career, together with, in a few instances, favourable conditions $(f=2)$ and expected long-term $(f=1)$ and financial $(f=1)$ benefits. Among the responses where an ultimate wish were 
Table 9. The frequency of student responses $(f=81)$ in SCCT variables

\begin{tabular}{|c|c|c|c|c|}
\hline Expressed career goals & Behavioural variables & Sub-variables & Frequency & Total (\%) \\
\hline \multirow{7}{*}{ STEM } & \multirow{3}{*}{ Interests } & Career interest & 12 & \multirow{3}{*}{$30(37.04 \%)$} \\
\hline & & Career-related activity interest & 12 & \\
\hline & & Career-related subject interest & 6 & \\
\hline & \multirow{2}{*}{ Outcome expectations } & Ultimate wishes & 11 & \multirow{2}{*}{$12(14.81 \%)$} \\
\hline & & Long-term benefits & 1 & \\
\hline & \multirow{2}{*}{ Self-efficacy } & Career fit & 3 & \multirow{2}{*}{$4(4.94 \%)$} \\
\hline & & Career-relevant self-efficacy & 1 & \\
\hline \multirow{10}{*}{ Non-STEM } & \multirow{3}{*}{ Interests } & Career interest & 7 & \multirow{3}{*}{$15(18.52 \%)$} \\
\hline & & Career-related activity interest & 7 & \\
\hline & & Career-related subject interest & 1 & \\
\hline & \multirow{3}{*}{ Outcome expectations } & Ultimate wishes & 10 & \multirow{3}{*}{$13(16.05 \%)$} \\
\hline & & Favourable conditions & 2 & \\
\hline & & Financial benefit & 1 & \\
\hline & \multirow{4}{*}{ Self-efficacy } & Career-relevant capability & 3 & \multirow{4}{*}{$7(8.64 \%)$} \\
\hline & & Career-relevant self-efficacy & 2 & \\
\hline & & Aptitude for the career & 1 & \\
\hline & & Career fit & 1 & \\
\hline
\end{tabular}

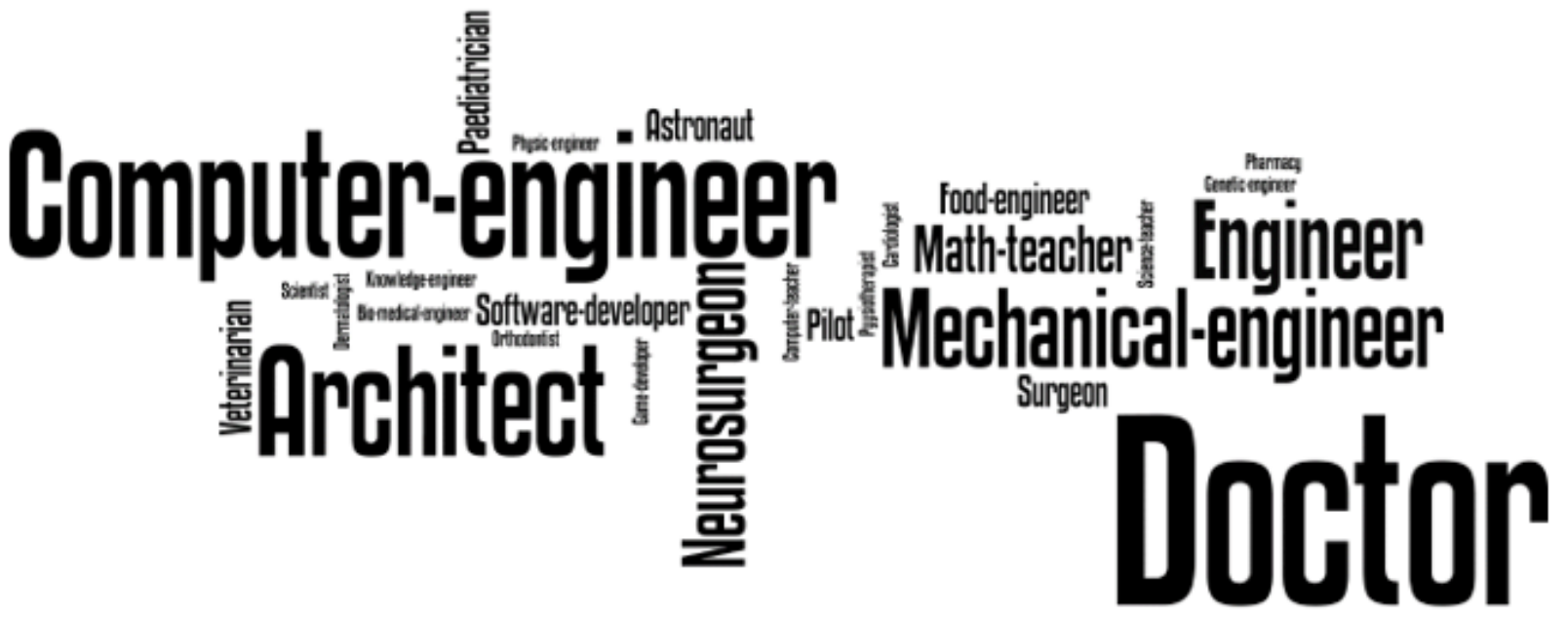

Figure 1. Wordle of expressed STEM professions in student responses $(f=71)$

mentioned, the two drivers of Turkish culture were implicit in students' career choice motives: altruism $(f=12)$ and patriotism $(f=6)$. The most mentioned careers within this group were doctor $(f=5)$, neurosurgeon $(f=3)$, soldier $(f=3)$, psychologist $(f=2)$, and mechanical engineering $(f=2)$. Typical examples involved: "I want to become a psychologist, because helping people makes me happy. I know some people who have psychological problems. When I help them, I feel good” (S55, grade 8, girl); and "I want to become a mechanical engineer because I want to make belicopters, planes that is useful for our army, country" (S71, grade 7, boy). One student wanted to become a mathematics teacher or a doctor because she wants "to do useful work for the country" (S104, grade 7).

Some other statements of career choice reasons referred to self-efficacy $(f=11,13.58 \%)$. Career fit $(f=4)$, careerrelevant self-efficacy $(f=3)$ or capability $(f=3)$, and aptitude for the career $(f=1)$ were attributed with career intentions by some students. Role model influence in the students' career choice was negligible. Only in two responses, a possible role model impact was detected. One student wrote: "Iudge, to having the same profession with my grandpa and dad and do a useful job for my country and people" (S13, grade 8, boy).

Figure 1 and Figure 2 show Wordle analysis of the expressed careers in student texts, categorised into two groups: STEM and non-STEM professions. As depicted in Figure 1, the STEM professions most commonly identified included doctor $(f=12)$, computer engineer $(f=8)$, architect $(f=7)$, engineer $(f=5)$, mechanical engineer $(f=5)$, and neurosurgeon $(f=5)$. The most identified non-STEM professions were psychologist $(f=5)$, policeman $(f=5)$, judge $(f=4)$, and lawyer $(f=4)$. 


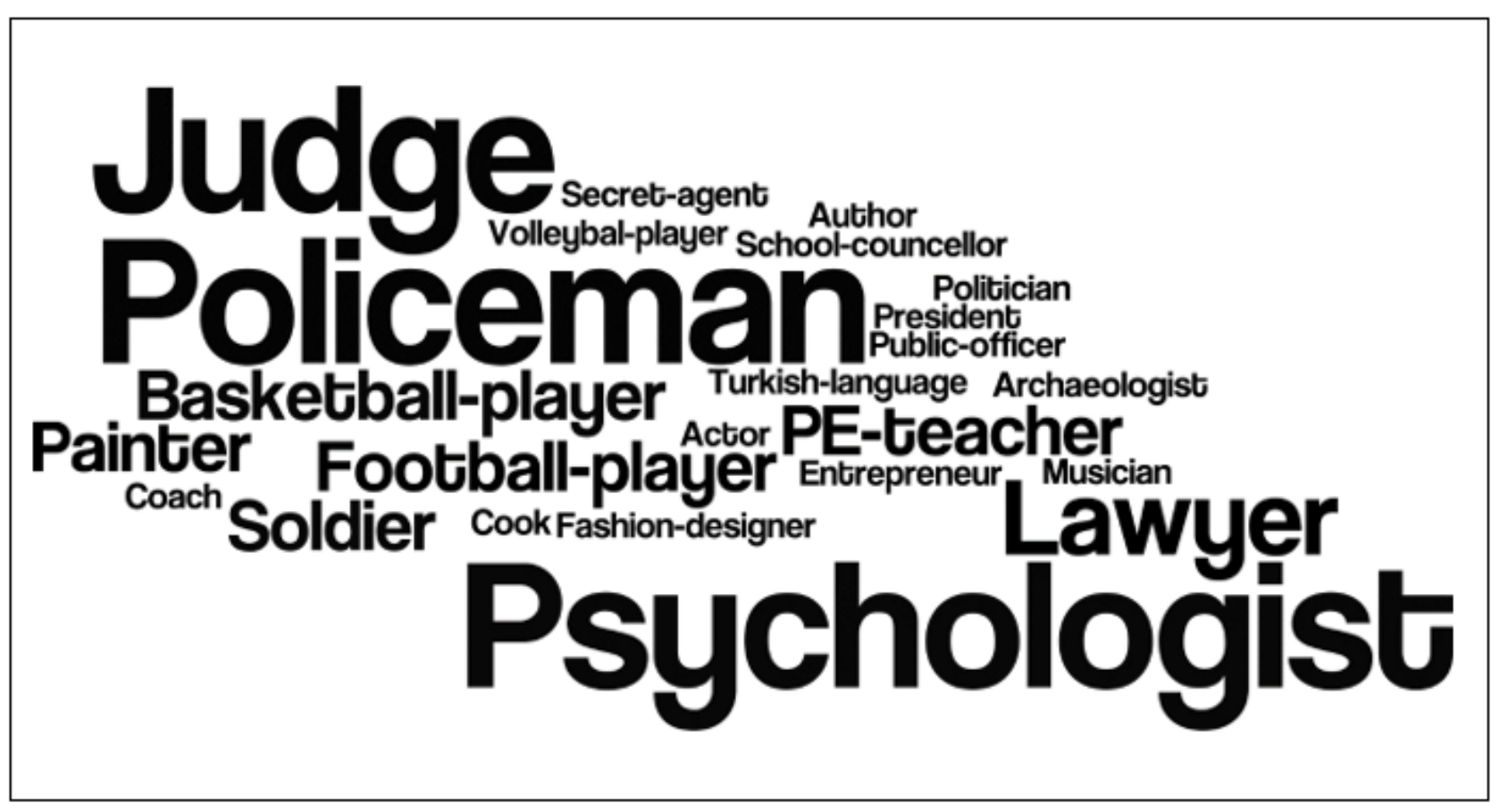

Figure 2. Wordle of expressed non-STEM professions in student responses $(f=43)$

\section{DISCUSSION, LIMITATIONS, AND IMPLICATIONS}

This paper provides empirical support for claims about school students from developing countries having positive orientations towards science and mathematics (e.g., Hatisaru, 2020b; Mullis et al., 2016; Sjøberg \& Schreiner, 2010; Thomas \& Watters, 2015). Participant students from Turkey maintained highly positive attitudes towards science, mathematics, technology and STEM careers, and moderate attitudes towards engineering. More students expressed interest in pursuing STEM-related careers after high school than non-STEM careers. The gender difference in students' attitudes towards STEM disciplines and careers was negligible. Both female and male students were highly positive towards science and mathematics. While male students were similarly highly positive towards engineering and technology, female students were only moderately positive towards these two disciplines. The gender difference in STEM orientation literature presents mixed results. While these findings regarding the difference between female and male students' attitudes towards STEM disciplines were consistent with Christensen et al. (2014), Sadler et al. (2012) reported trends that female students were less likely to pursue STEM careers. Both studies were undertaken in developed countries; in this study conducted in Turkey, females' attitudes towards STEM disciplines and careers were positive. In fact, in TIMSS 2015, grade eight Turkish female students performed better than Turkish male students in science (Mullis, Martin, \& Loveless, 2016).

This study highlights the possible influence of various factors related to when students make their educational or career choices. SCCT posits the role and importance of behavioural variables including self-efficacy, interests, outcome expectations, and goals in individuals' career decisions. Overall, one of the critical determinants of the participant students' career intentions was interests. Several students associated their interests with a specific career (e.g., mechanical engineering), or activities (e.g., making cars) and/or subjects (e.g., mathematics) related to that career. The results revealed that outcome expectations may play somewhat different roles in students' career choice process. Potential long-term benefits such as professional income, which were only mentioned by a few lower secondary students in this study, may be more influential on high school students' career interests and choices (Bahar \& Adiguzel, 2016; Prieto \& Dugar, 2017). While interests and outcome expectations were the main motivations for students' career choice after high school, consistent with previous research (e.g., Bandura et al., 2001; Prieto \& Dugar, 2017), students' self-efficacy was also influential.

Where students expressed that it was their ultimate wish to choose a particular career, it was evident that societal and/or cultural factors influenced their career intentions. SCCT elaborates on how larger, societal context can influence career choice decisions. Specifically, several students' responses revealed that they wanted to become a doctor or psychologist to help others with their health or mental health issues. A few students wanted to assist the army by becoming a soldier or mechanical engineer. Implicit in the motives of these students' career choices are two drivers of Turkish society, altruism, and patriotism (Evason, 2017), which highlights the possible societal influence on their career goals. In the last Teaching and Learning International Survey (TALIS 2018), teachers across 
the world attributed altruistic motivations such as, "teaching allowed [me] to influence the development of children and young people" for becoming a teacher (OECD, 2019, p. 123). Interestingly, in this study, few students (S9 and S104) mentioned wanting to become a teacher. In Turkish society, although all professions are valued, a career in medicine or engineering is viewed as more prestigious than a career in teaching. The students' lack of interest in a teaching career may again indicate that the context and social expectations influence students' educational choices (Bahar \& Adiguzel, 2016).

In summary, the present study illustrates the suitability of the SCCT framework (Lent et al., 1994; 2000) for investigating the determinants of school students' STEM career intentions. According to SCCT, behavioural variables shape individuals' educational and occupational choices (Lent et al., 2010), and various important contextual variables such as culture and educational climate impact on these behavioural variables (Lent et al., 2000). Educational investments which take into consideration these variables have the potential to influence school students' attitudes towards and career choices in STEM. In particular, the influence of personal interests and societal factors on students' educational choices need to be considered in the development and implementation of STEM initiatives that aiming to impact students' orientations towards STEM.

\section{Limitations}

The aims of this paper were to investigate Turkish lower secondary students' attitudes towards STEM disciplines and careers, and the influence of behavioural, personal, and contextual variables on their career intentions in STEM. Interests and ultimate wishes, or altruistic motives, have been highlighted as important determinants of students' career goals. Nevertheless, these findings are not an exact measure of the influence of, for instance, early life experiences (Tai, Liu, Maltese, \& Fan, 2006), academic achievement (Wang, 2013), perceived classroom learning experiences (Lyons, 2006), or influence of role models (Sasson, 2020) involving parents and teachers (Bahar \& Adiguzel, 2016; Sjaastad, 2012). Answers to the open-ended item concerning the reasons of expressed career goals, represent the students' response at that point in time and within that classroom context. It is not possible to measure the precise range of behavioural or environmental influences on student choice, and intentions to pursue STEM careers may exist that were not mentioned by the students cannot be excluded. A second limitation relating to external validity also exists. It is not known whether the determinants of the students' career intentions found in this study are the result of the specific characteristics of students who participated in this study, or whether they are representative of a general trend in the population from which the sample has been drawn. Thus, the findings may not be generalisable to other schools in Ankara or to other regions in Turkey. Further research in this area including different and more in-depth research instruments, can be applied to meet these limitations. Nevertheless, the findings presented here provide valid and valuable insight into the motives that lie behind school students' career intentions in STEM. Together the quantitative data, students' responses to openended item, and the theoretical underpinnings of the research, all strengthen the validity of the study and to the conclusions drawn.

\section{Implications}

The findings reveal that behavioural SCCT variables operate as guides and motivators of students' career intentions and point to several implications. The diminishing inclination of school students to pursue STEMrelated careers can be influenced by interventions that encompass and/or influence student interests. After school programmes and initiatives that provide students informal learning experiences in STEM such as robotics summer camps, media/toy design projects, and science fairs (e.g., Ayar, 2015; Gülgün, 2019; Karahan et al., 2015; Sirinterlikci et al., 2019) demonstrate how such educational investments might work. Considering the likelihood that educational experiences before high school may have an important influence on future occupational plans, early exposure to the sciences can increase student competence and interest in STEM careers (Sasson, 2020; Tai et al., 2006)

The attainment of STEM qualifications within Turkey's young population is ultimately important to the progress of the Turkish economy (Kivanc et al., 2017). As government aims to propel Turkey into the top ten largest economies in the world by 2023 (Istanbul Chamber of Industry, 2016), the country needs to enhance its competitiveness by building up its human resources (World Economic Forum, 2013). Even though students attribute importance to mathematics and science learning (e.g., Hatisaru, 2020b; Mullis et al., 2016), and express interest into studies in STEM (Ayar, 2015; Kearney, 2016), statistics show that the number of graduates and new admissions in technical and quantitative fields remain disproportionately low (Ayar, 2015). The current attrition in STEM degrees will ultimately result in skill shortages by 2023 (Kivanc et al., 2017). Student continuation in science and quantitative disciplines and progression towards careers in these fields (i.e. success) can only be achieved within an educational system where students' goals complement their career-relevant knowledge and skills. To achieve such a system, resources must be available at both institutional and programme level (Jolly et al., 2004). Effective 
ways to transform students' positive attitudes towards and interest in STEM disciplines and careers to success, need to be understood and followed by comprehensive approaches to creating the environment for student success (Jolly et al., 2004). It is especially important that students who commence university studies are better informed about the knowledge and skills required for entering certain STEM fields (Prieto \& Dugar, 2017). Career guidance should be strengthened within the education system (Kearney, 2016), for "both to ensure that the country [in this case Turkey] has the skills its needs for the economy and to enable young people to make the best choices to meet their own future needs and aspirations" (Tripney et al., 2010).

This research has found the conceptualisation of behavioural, personal, and contextual factors in students' STEM career goals based upon the SCCT framework proposed by Lent et al. $(1994,2000)$ useful, for capturing the various ways in which these variables can be mediated to inspire school students' academic choices. Future research into STEM career interests and interventions needs to consider the contextual aspects of career choice behaviours (Lent et al., 2000), as in this study they were found to be operating as guides for students' future career plans. For example, there has been a significant decline in undergraduate mathematics enrolments in Turkey (Nesin, 2014), with the Council of Higher Education indicating that of the total undergraduate population (in 2019, it was over 2 million), only 1.12\% enrolled in a mathematics major in 2015. In 2016 and 2017, there was a dramatic decline in enrolments $(0.36 \%$ in $2016 ; 0.50 \%$ in $2017 ; 1.41 \%$ in 2018$)$ possibly because in those years, mathematics graduates were not entitled to become school mathematics teachers. This example indicates that employment market conditions for mathematics graduates may influence students' decisions about whether to study mathematics and possibly their interest in mathematics.

The study reported here, in combination with the findings of the larger study (Hatisaru, in press), have implications for future research. These combined results suggest, albeit tentatively, that students' perceptions of teaching and learning practices in mathematics classrooms in Turkey (teachers transmit information and demonstrate correct solutions while students are passive recipients), play little role in the career intentions. This finding stimulates further research focussed on investigating the ways in which classroom learning experiences associate with the career choice process. Current research suggests that more open-ended and inquiry-based methods of learning are important for both 'screening' students who are truly inclined and committed to STEM disciplines (Thomas \& Watters, 2015) and for improving the quality of learning and assisting studying STEM subjects at university level (Kearney, 2016). Hence, a thorough understanding of the ways in which such perceived teacher-centred instructional approaches affect educational choices and outcomes (e.g., Lyons, 2006) in the long term is necessary.

\section{ACKNOWLEDGEMENTS}

I am grateful to the schools and students for participating in this study. I thank Ismail Yolcu and Emily Morgan for their assistance in data collection and coding, and Ersoy Karabay for assisting with statistical analyses and thoughtful conversations.

\section{REFERENCES}

Afari, E., Aldridge, J. M., Fraser, B. J., \& Khine, M. S. (2013). Students' perceptions of the learning environment and attitudes in game-based mathematics classrooms. Learning Environments Research, 16, 131-150. https://doi.org/10.1007/s10984-012-9122-6

Australian Academy of Sciences. (2016). The mathematical sciences in Australia: A vision for 2025. Canberra: Australian Academy of Science.

Ayar, M. C. (2015). First-hand experience with engineering design and career interest in engineering: An informal STEM education case study. Educational Sciences: Theory and Practice, 15(6), 1655-1675.

Bahar, A, \& Adiguzel, T. (2016). Analysis of factors influencing interest in STEM career: Comparison between American and Turkish high school students with high ability. Journal of STEM Education: Innovations and Research, 17(3), 64-69.

Bandura, A., Barbaranelli, C., Caprara, G. V., \& Pastorelli, C. (2001). Self-efficacy beliefs as shapers of children's aspirations and career trajectories. Child Development, 72(1), 187-206. https:// doi.org/10.1111/1467-8624.00273

Barrington, F., \& Evans, M. (2014). Participation in year 12 mathematics 2004-2013. Australian Mathematical Sciences Institute. https://amsi.org.au/publications/participation-year-12-mathematics-2004-2013/

Christensen, R., Knezek, G., \& Tyler-Wood, T. (2014). Student perceptions of science, technology, engineering and mathematics (STEM) content and careers. Computers in Human Behavior, 34, 173-186. https:// doi.org.10.1016/j.chb.2014.01.046 
Edzie, R. L. (2014). Exploring the factors that influence and motivate female students to enroll and persist in collegiate STEM degree programs: A mixed methods study. https://doi.org/10.1109/IEEEGCC.2013 .6705815

Elo, S., \& Kyngäs (2008). The qualitative content analysis process. Journal of Advanced Nursing 62(1), 107-115. https://doi.org.10.1111/j.1365-2648.2007.04569.x

European Schoolnet (2018, October). Science, technology, engineering, and mathematics education policies in Europe. Scientix observatory report. European Schoolnet, Brussels.

Eurydice. (2011). Mathematics education in Europe: Common challenges and national policies, Education, Audiovisual and Culture Executive Agency. Available at: http://eacea.ec.europa.eu/education/eurydice/ documents/thematic_reports/132en.pdf (Accessed 21 December 2018).

Evason, N. (2017). Turkish culture. Available at: https://culturalatlas.sbs.com.au/turkish-culture. (Accessed 19 July 2020).

Fraser, B. (2014). Classroom learning environments: Historical and contemporary perspectives. In Lederman, N. \& Abell, S. (eds), Handbook of Research on Science Education Volume II (pp. 104-119). USA: Routledge.

Grinis, I. (2019). The STEM requirements of "Non-STEM" jobs: Evidence from UK online vacancy postings. Economics of Education Review, 70, 144-158. https:// doi.org/10.1016/j.econedurev.2019.02.005

Gülgün, C., Yılmaz, A., Avan, Ç., Ertuğrul Akyol, B., \& Doğanay, K. (2019). TÜBİTAK tarafindan desteklenen bilim şenliklerine (4007) yönelik ilkokul ve ortaokul ögrencilerinin ve atölye liderlerinin görüşlerinin belirlenmesi. [Determination of the views of primary, secondary school students and workshops leaders about science fairs supported by TUBITAK (4007)]. Bilim, Teknoloji, Mühendislik, Matematik ve Sanat (J-STEAM) Ë̆itim Dergisi, 2(1), 52-67.

Hasni, A., \& Potvin, P. (2015). Student's interest in science and technology and its relationships with teaching methods, family context and self-efficacy. International Journal of Environmental and Science Education, 10, 337-366.

Hatisaru, V. (2020a). Exploring evidence of mathematical tasks and representations in the drawings of middle school students. International Electronic Journal of Mathematics Education, 15(3), 1-21. https://doi.org/10.29333/iejme/8482

Hatisaru, V. (2020b). Perceived need for mathematics among lower secondary students. Australian Mathematics Education Journal, 2(1), 9-14.

Hatisaru, V. (in press). School students' depictions of mathematics teaching and learning practices. International Electronic Journal of Elementary Education.

Hatisaru, V., \& Kucukturan, A. G. (2011). The effect of problem-based learning on mathematics achievement of 9th grade industrial vocational high school students. Journal of Contemporary Education, 36(382), 29-38.

Hmelo-Silver, C. E. (2004). Problem-based learning: What and how do students learn? Educational Psychology Review, 16, 235-266. https://doi.org/10.1023/B:EDPR.0000034022.16470.f3

Istanbul Chamber of Industry (2016). Trust in Turkey produce in Turkey, Istanbul Chambers of Industry Corporate Communications. Available at: http://www.iso.org.tr/sites/1/upload/files/ISO-trustinturkey-web-5840.pdf (Accessed 15 July 2019).

Jolly, E., Campbell, P., \& Perlman, L. (2004). Engagement, capacity, and continuity: A trilogy for student success. Minneapolis, MN: GE Foundation.

Karahan, E., Canbazoğlu-Bilici, S., \& Ünal, A. (2015). Integration of media design processes in science, technology, engineering, and mathematics (STEM) education. Eurasian Journal of Educational Research, 60, 221-240. https://doi.org/10.14689/ejer.2015.60.15

Kearney, C. (2016). Efforts to increase students' interest in pursuing mathematics, science and technology studies and careers. National measures taken by 30 countries - 2015 report. European Schoolnet, Brussels.

Kier, M. W., \& Blanchard, M. R. (2021). Eliciting students' voices through STEM career explorations. International Journal of Science and Mathematics Education, 19, 151-169. https:// doi.org/10.1007/s10763-019-10042-z

Kivanc, O., Sener, S., Mumcuogullari, A., \& Sunacoglu, Z. (2017). The STEM need in Turkey for 2023, The Turkish Industry and Business Association (TUSIAD). Available at: https://tusiad.org/en/reports/item/9754-the-stemneed-in-turkey-for-2023 (Accessed 9 July 2019).

Knipprath et al., (2018). STEM education in Flanders: how STEM@school aims to foster STEM literacy and a positive attitude towards STEM. IEEE Instrumentation \& Measurement Magazine, 21(3), 36-40. https://doi.org/10.1109/MIM.2018.8360917

Lent, R. W. (2005). A social cognitive view of career development and counselling. In S. D. Brown \& R. W. Lent (eds), Career development and counselling: Putting theory and research to work (pp. 101-127). John Wiley \& Sons Inc.

Lent, R. W., Brown, S. D., \& Hackett, G. (1994). Toward a unifying social cognitive theory of career and academic interest, choice, and performance [Monograph]. Journal of Vocational Behaviour, 45, 79-122. https://doi.org/10.1006/jvbe.1994.1027 
Lent, R. W., Brown, S. D., \& Hackett, G. (2000). Contextual supports and barriers to career choice: A social cognitive analysis. Journal of Counselling Psychology, 47, 36-49. https:/ / doi.org/10.1037/0022-0167.47.1.36

Lent, R. W., Sheu, H-B., \& Gloster, C. S., \& Wilkins, G. (2010). Longitudinal test of the social cognitive model of choice in engineering students at historically Black universities. Journal of Vocational Behavior, 76, 387-394. https://doi.org/10.1016/j.jvb.2009.09.002

Lyons, T. (2006). Different countries, same science classes: Students' experiences of school science in their own words. International Journal of Science Education, 28(6), 591-613. https:/ / doi.org/10.1080/09500690500339621

Maltese, A., \& Tai, R. S. (2010). Pipeline persistence: Examining the association of educational experiences with earned degrees in STEM among U.S. students. Science Education, 95, 877-907. https://doi.org/10.1002/sce.20441

Mullis, I. V. S., Martin, M. O., \& Loveless, T. (2016). 20 years of TIMSS. International trends in mathematics and science achievement, curriculum, and instruction, Boston College, TIMSS \& PIRLS International Study Center. Available at: http://timssandpirls.bc.edu/timss2015/international-results/ (Accessed 19 June 2019).

Mullis, I. V. S., Martin, M. O., Foy, P., \& Hooper, M. (2016). TIMSS 2015 international results in mathematics, Boston College, TIMSS \& PIRLS International Study Center. Available at: http://timssandpirls.bc.edu/timss2015/international-results/ (Accessed 19 June 2019).

Narli, S. (2010). An alternative evaluation method for Likert type attitude scales: Rough set data analysis. Scientific Research and Essays, 5(6), 519-528.

Nesin, A. (2014, August). 2023 icin cok gec, belki 2073! [Too late for 2023, perhaps 2073!]. Gorus, 85, 24-26.

OECD (2019). TALIS 2018 results (Volume I): Teachers and school leaders as lifelong learners. TALIS, OECD Publishing: Paris. https:// doi.org/10.1787/1d0bc92a-en

Office of the Chief Scientist. (2012). Mathematics, engineering, and science in the national interest. Canberra: Commonwealth of Australia.

Potvin, P., \& Hasni, A. (2014). Interest, motivation and attitude towards science and technology at K-12 levels: A systematic review of 12 years of educational research. Studies in Science Education, 50(1), 85-129. https://doi.org/10.1080/03057267.2014.881626

Prieto, E., \& Dugar, N. (2017). An enquiry into the influence of mathematics on students' choice of STEM careers. International Journal of Science and Mathematics Education, 15, 1501-1520. https://doi.org/10.1007/s10763-0169753-7

Sadler, P. M., Sonnert, G., Hazari, Z., \& Tai, R. (2012). Stability and volatility of STEM career interest in high school: A gender study. Science Education, 96(3), 411-427. https://doi.org/10.1002/sce.21007

Sasson, I. (2020). Becoming a scientist - Career choice characteristics. International Journal of Science and Mathematics Education. https://doi.org/10.1007/s10763-020-10059-9

Saunders, B., Sim, J., Kingstone, T., Baker, S., Waterfield, J., Bartlam, B., ... Jinks, C. (2017). Saturation in qualitative research: Exploring its conceptualization and operationalization. Quality and Quantity, 52, 1893-1907. http://doi.org/10.1007/s11135-017-0574-8

Sirinterlikci, A., Zane, L., \& Sirinterlikci, A. (2009). Active learning through toy design and development. Journal of Technology Studies, 35(2), 14-22. https://doi.org/10.21061/jots.v35i2.a.2

Sjaastad, J. (2012). Sources of inspiration: The role of significant persons in young people's choice of science in higher education. International Journal of Science Education, 34(10), 1615-1636. https:// doi.org/10.1080/09500693 .2011 .590543

Sjøberg, S., \& Schreiner, C. (2010). The ROSE project: An overview and key findings. University of Oslo, March 2010.

Tai, R., Qi, L. C., Maltese, A., \& Fan, X. (2006). Career choice. Planning early for careers in science. Science, 312(5777), 1143-1144. https://doi.org/10.1126/science.1128690

Thomas, B., \& Watters. J. J. (2015). Perspectives on Australian, Indian and Malaysian approaches to STEM education. International Journal of Educational Development, 45, 42-53. https://doi.org/10.1016/j.ijedudev.2015 .08 .002

Tripney, J., Newman, M., Bangpan, M., Niza, C., Mackintosh, M., \& Sinclair, J. (2010). Factors influencing young people (aged 14-19) in education about STEM subject choices: A systematic review of the UK literature. London, United Kingdom: EPPI.

Wang, X. (2013). Why students choose STEM majors: Motivation, high school learning, and postsecondary context of support. American Educational Research Journal, 50(5), 1081-1121. https://doi.org/10.3102/ 0002831213488622

World Economic Forum (2013). The human capital report, World Economic Forum. Available at: http:// www3.weforum.org/docs/WEF_HumanCapitalReport_2013.pdf (Accessed 21 July 2019). 
European Journal of STEM Education, 2021, 6(1), 02

\section{APPENDIX A: Determinants of student career choice corresponding to SCCT variables}

\begin{tabular}{|c|c|c|c|}
\hline Goals & $\begin{array}{l}\text { Behavioural } \\
\text { variables }\end{array}$ & Sub-variable & Example \\
\hline \multirow[t]{12}{*}{$\begin{array}{l}\text { Expressed } \\
\text { STEM/ } \\
\text { non-STEM } \\
\text { careers }\end{array}$} & \multirow[t]{4}{*}{ Interests } & Career interest & $\begin{array}{l}\text { "Software developer or computer engineering because I am interested in." } \\
\text { (S83, grade 6, boy) } \\
\text { "I want to study law and become a lawyer because it interests me." (S43, grade } \\
8 \text {, girl) }\end{array}$ \\
\hline & & $\begin{array}{l}\text { Career-related activity } \\
\text { interest }\end{array}$ & $\begin{array}{l}\text { "I will become a PE teacher because I like sport and want to make it my } \\
\text { profession." (S27, grade } 8 \text {, boy) } \\
\text { "Pilot because I like planes much and [being a pilot] is a proud for my country. } \\
\text { Painter, I have interest in paintings." (S18, grade } 8 \text {, girl) }\end{array}$ \\
\hline & & $\begin{array}{l}\text { Career-related subject } \\
\text { interest }\end{array}$ & $\begin{array}{l}\text { "I want to become a doctor because I like science and maths very much and } \\
\text { feel happy when I succeed." (S36, grade 8, girl) }\end{array}$ \\
\hline & & & "Engineering, I am interested in maths." (S15, grade 8, girl) \\
\hline & \multirow[t]{4}{*}{$\begin{array}{l}\text { Outcome } \\
\text { expectations }\end{array}$} & Ultimate wishes & $\begin{array}{l}\text { "After high school I want to become a Neurosurgeon. I like helping people. I } \\
\text { want, after a surgeon, seeing that person becomes well." (S80, grade 6, girl) } \\
\text { "I want to be a Soldier because I want defending my land, people very much." } \\
\text { (S98, grade 7, boy) }\end{array}$ \\
\hline & & Favourable conditions & $\begin{array}{l}\text { "Public officer. Job conditions are convenient: off weekend, no stress." (S90, } \\
\text { grade 7, boy) }\end{array}$ \\
\hline & & Long-term benefits & $\begin{array}{l}\text { "After completing high school, I like to become a computer engineering, } \\
\text { which is a future profession and suits me." (S22, grade } 8 \text {, boy) }\end{array}$ \\
\hline & & Financial benefit & $\begin{array}{l}\text { "I will become a judge because they earn well. And it is nice." (S103, grade } 7 \text {, } \\
\text { boy) }\end{array}$ \\
\hline & \multirow[t]{4}{*}{ Self-efficacy } & Career fit & $\begin{array}{l}\text { "I want to be a psychologist or volleyball player because I find these } \\
\text { professions suitable for me." (S63, grade 7, girl) }\end{array}$ \\
\hline & & $\begin{array}{l}\text { Career-relevant self- } \\
\text { efficacy }\end{array}$ & $\begin{array}{l}\text { "Science teacher. I like science subject much and achieve. Veterinarian, I like } \\
\text { pets and think succeed it." (S9, grade 8, girl) }\end{array}$ \\
\hline & & $\begin{array}{l}\text { Career-relevant } \\
\text { capability }\end{array}$ & $\begin{array}{l}\text { "I want to become a basketball player. The reason is I am skilled in this area } \\
\text { and believe can make a good career." ( } \mathrm{S} 37 \text {, grade } 7 \text {, boy) }\end{array}$ \\
\hline & & Aptitude for the career & "Acting because I am good at memorising and I want to." (S102, grade 7 , girl) \\
\hline
\end{tabular}

